\title{
Editorial
}

\section{Is there such a thing as myofascial pain?}

Is there such a thing as myofascial pain? It is certainly imbedded in our medical lingo.

But many practitioners deny it - until, perhaps, the surgery has failed (or should we say surgeon has not succeeded?) The patient continues to complain of pain; the physician can't find a reason; and the surgeon recommends a MRI with gadolinium - a procedure which reveals 'scar tissue'.

What next?

Some would suggest algometry and local injections of 'tender' points. Others would recommend a CARF accredited interdisciplinary chronic pain management program.

That's my choice! For the following reasons:

- Measuring pain with quantitative stimuli is only half of the story.

- The more variable reaction is the patient's response. The nociceptive impulse from the soft tissue could be the least important (Ergo - why spend all the time to quantitate?)

- Innumberable possibilities at the CNS level will determine the final outcome. Considerations include memory of pain, state of activation of CNS, culture, significance of pain (this is the most important variable to alter by education), personal characteristics, e.g. ego strength, support by family and friends, and economic prospects among many others.

The notion that there can be a simplistic medical or surgical solution to chronic soft tissue (otherwise known as myofascial) pain is incredibly naive, as well as mediocre medicine.

Pain is ubiquitous, often confusing, always immeasurable, and must be managed in a comprehensive, interdisciplinary (not multidisciplinary) team setting, especially if it is pervicacious.

To seek a facile prosaic remedy will be futile and could be harmful and almost certainly complicating to the healing process.

Ernest W. Johnson, MD 